\title{
Inflammatory Pseudotumor of the Liver: Clinical Case
}

\author{
Cristina Lameirão Gomes Nuno Silva José Presa Ramos
}

Liver Unit, Internal Medicine Department, Centro Hospitalar de Trás-os-Montes e Alto Douro, Vila Real, Portugal

\section{Keywords}

Inflammatory pseudotumor of the liver - Liver biopsy .

Nonsteroidal anti-inflammatory drugs

\section{Pseudotumor inflamatório do fígado: caso clínico}

\section{Palavras Chave}

Pseudotumor inflamatório do fígado · Biópsia hepática .

Anti-inflamatórios não esteroides

The authors present the case of an 81-year-old man with hypertension and alcohol consumption (60-80 g/ day) who was admitted to the Emergency Department with abdominal pain in the upper right quadrant, with 1 month of evolution, diarrhea (5-6 liquid stools per day), and slimming of $10 \mathrm{~kg}$ in the past 2 months. He had no fever or stigmas of alcoholic liver disease. Analytically, he had no increase in inflammatory markers, but because of these complaints, an abdominal computed tomography was performed, which showed a bulky mass. The mass occupied almost the whole right lobe of the liver, measured $14.5 \mathrm{~cm}$ of greater axis, and had well-defined contours and signs of intralesional necrosis at the central

\section{KARGER}

E-Mail karger@karger.com www.karger.com/pjg
(C) 2018 Sociedade Portuguesa de Gastrenterologia

Published by S. Karger AG, Basel

Karcer

Open access

This article is licensed under the Creative Commons AttributionNonCommercial-NoDerivatives 4.0 International License (CC BYNC-ND) (http://www.karger.com/Services/OpenAccessLicense). Usage and distribution for commercial purposes as well as any distribution of modified material requires written permission. level. The patient was referred to the Ambulatory Liver Unit. In the first evaluation, a hard mass in the upper right quadrant was detected, with well-defined limits and slightly painful to deep palpation. In the etiological study, we highlight: hemoglobin 9.27 g/dL (normal: 13-18), mean corpuscular volume 109 fL (normal: 87-103), mean corpuscular hemoglobin (HGM) $35.3 \mathrm{pg}$ (normal: 27-33), leukocytes 5,000/ $\mu \mathrm{L}$ (normal: 4,000-11,000), platelets $377,000 / \mu \mathrm{L}$ (normal: 150,000-400,000), aspartate aminotransferase $33 \mathrm{U} / \mathrm{L}$ (normal: <40), alanine aminotransferase $23 \mathrm{U} / \mathrm{L}$ (normal: <41), gamma-glutamyltransferase $96 \mathrm{U} / \mathrm{L}$ (normal: 10-49), total bilirubin 0.6 $\mathrm{mg} / \mathrm{dL}$ (normal: <1.2), albumin $3.6 \mathrm{~g} / \mathrm{dL}$ (normal: $3.4-$ 4.8), alkaline phosphatase 99 U/L (normal: 40-130), Creactive protein $0.6 \mathrm{mg} / \mathrm{dL}$ (normal: $<0.5$ ), normal coagulation, renal function, and ionogram, negative viral serology (hepatitis B virus, hepatitis $C$ virus, and human immunodeficiency virus), tumor markers: alpha-fetoprotein $2.2 \mathrm{IU} / \mathrm{mL}$ (normal: 1-8), carcinoembryonic antigen $2.3 \mathrm{ng} / \mathrm{mL}$ (normal: <0.5), and CA19.9 $77 \mathrm{U} / \mathrm{mL}$ (normal: 0-37). In order to better characterize the nodule, abdominal magnetic resonance imaging was performed, which described a well-circumscribed contour lesion, showing a halo with a solid internal structure with 

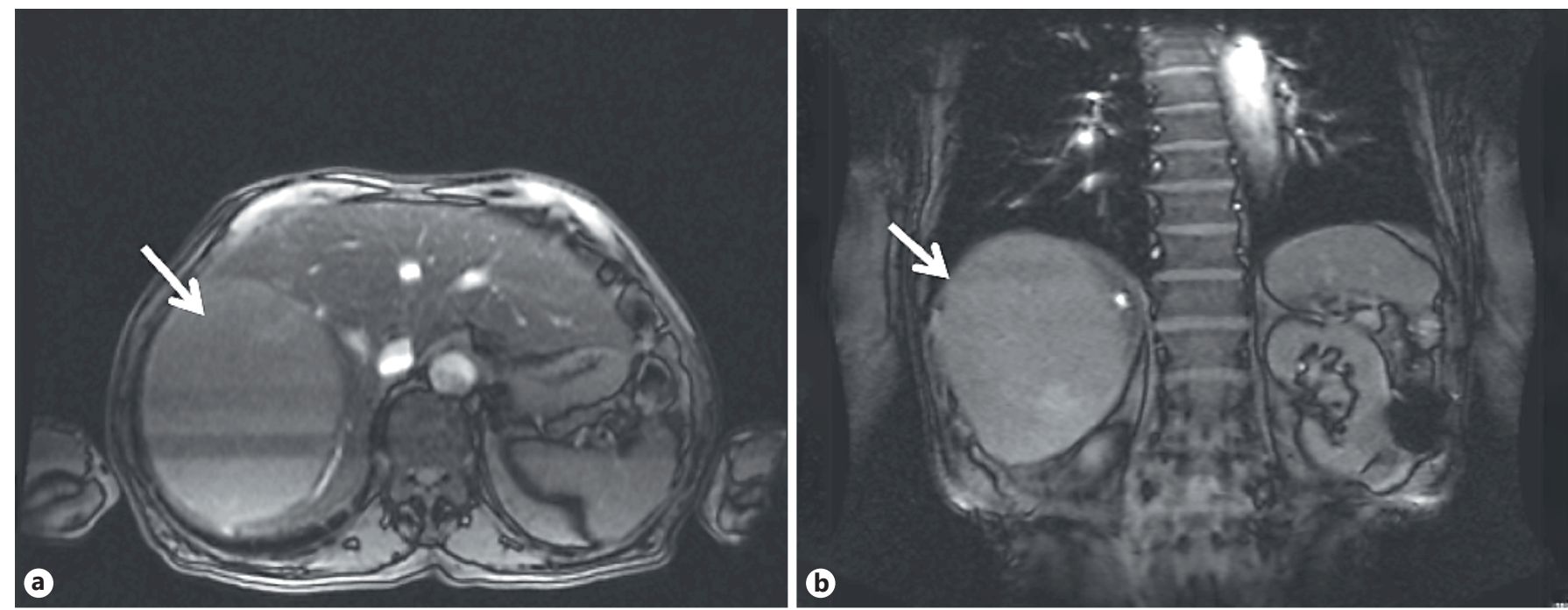

Fig. 1. Abdominal magnetic resonance. a Axial T1 Fat-Sat after contrast. b Coronal T1 after contrast. c Axial T1 Fat-Sat (portal phase): a huge nodular lesion occupying most of the right lobe, measuring approximately $14 \mathrm{~cm}$ in longitudinal diameter, $13.5 \mathrm{~cm}$ in anteroposterior, and $10 \mathrm{~cm}$ in cross-section. It is a well-circumscribed external contour lesion, showing a capturing halo with a solid internal structure, with a heterogeneous contrast. There is a small lobulation of its external contour, and it is not entirely clear whether there are secondary lesions or lobules of the dominant lesion. Several small hepatic nodules, at least ten, dispersed, and having a large diameter varying from about $4 \mathrm{~mm}$ to $28 \mathrm{~mm}$, the last one in segment II. In this context, it is probably a hepatocellular carcinoma with multiple satellite lesions.

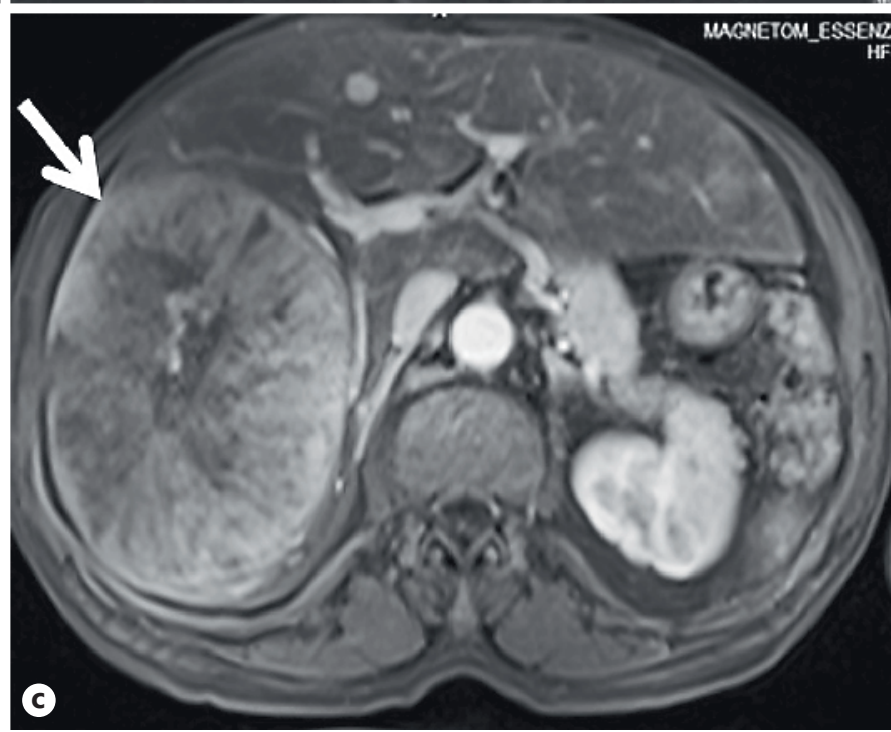

Fig. 2. Transjugular liver biopsy (a, b; 40x, hematoxylin-eosin staining) shows pieces of hepatic tissue, totally replaced by connective tissue (asterisk) accompanied by a moderate inflammatory infiltrate, predominately lymphoplasmacytic (arrow), accompanied by vascular congestion with erythrocyte overflow.
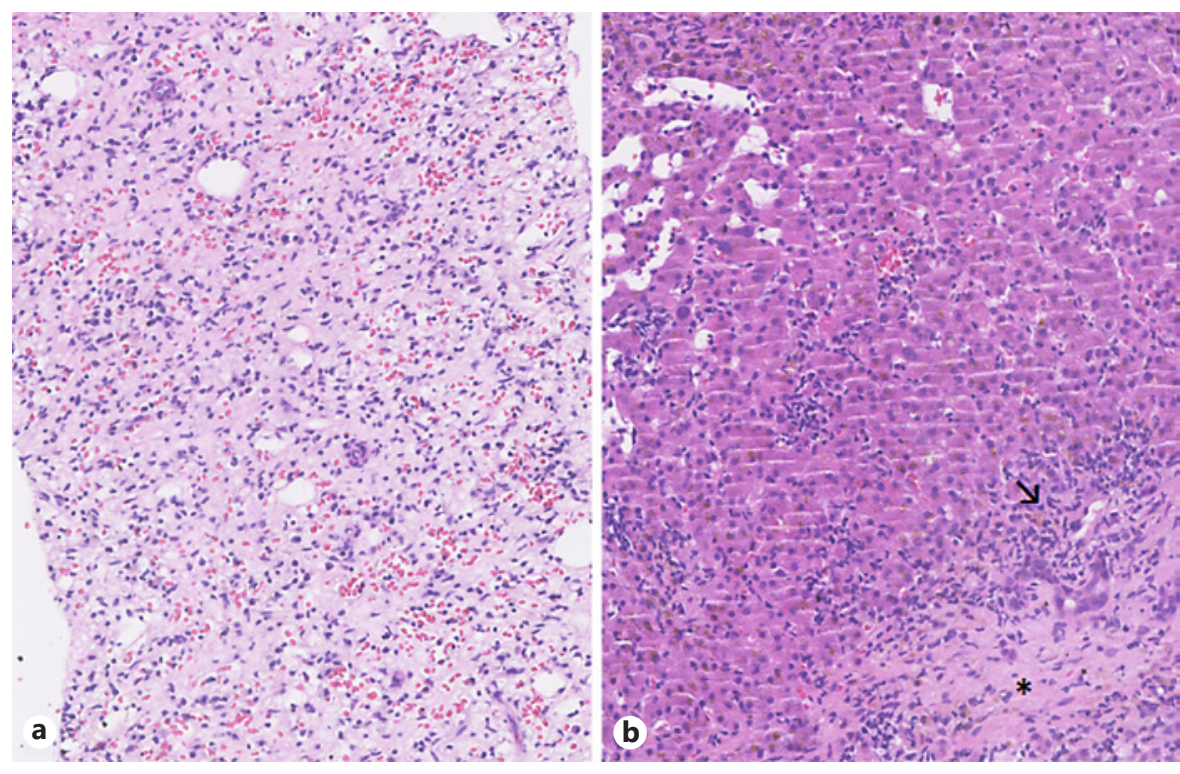


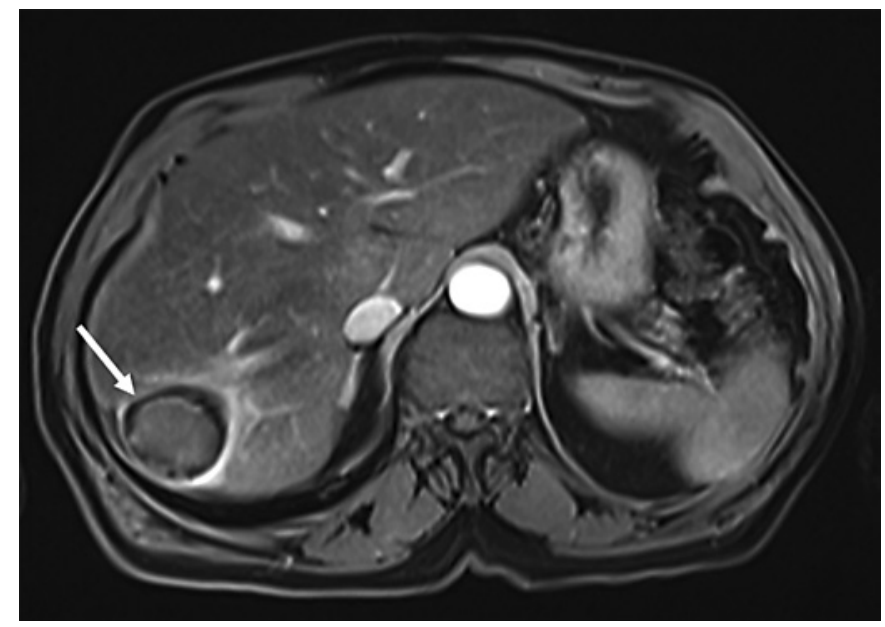

Fig. 3. Abdominal magnetic resonance (axial T1 Fat-Sat after contrast [portal phase]): inflammatory pseudotumor of the liver: in segment VII, a nodularity is detected in the capsule of $2.2 \mathrm{~mm}$ of heterogeneous content and intense uptake of the contrast product, measuring $41 \times 45 \mathrm{~mm}$ in the axial plane, and absence of other hepatic nodularities.

heterogenous contrast uptake, which was interpreted as a probable hepatocellular carcinoma with several satellite lesions; the suprahepatic veins, the portal vein, and the hepatic artery remain permeable, with no other changes (Fig. 1). A liver biopsy was performed, which revealed histologic pattern of an inflammatory pseudotumor of the liver (IPT) (Fig. 2). He started nonsteroidal anti-inflammatory drugs (naproxen $500 \mathrm{mg} /$ day), and about 1 year after starting the treatment, he was asymptomatic. He repeated imaging 1.5 years afterwards, which revealed a significant reduction of the hepatic lesion, cur- rently measuring $41 \times 45 \mathrm{~mm}$ (Fig. 3 ). He maintained treatment for 2 years and trimestral follow-up in the Ambulatory Liver Unit.

IPT is a rare benign lesion with only about 300 cases described in the literature [1]. It predominantly affects children and young adults (predominance of the 3rd decade), but can occur at any age, being more frequent in the Asian population, predominantly in males $[2,3]$. The etiology and pathogenesis remain unknown, but it is assumed that it may result from an exaggerated inflammatory response directed to a particular aggression (inflammatory, infectious, autoimmune, trauma, or surgical processes) $[2,4]$. IPT can appear as a single mass or multiple masses characterized histologically by the proliferation of fibroblasts and inflammatory cells $[4,5]$. Diagnosis of IPT is challenging, because there are no clinical symptoms, signs, or laboratory or pathognomonic imaging of this pathology, often leading to an incorrect diagnosis [2]. Liver biopsy is necessary to establish a definitive diagnosis $[2,3,5]$. Treatment can be done with antibiotics, nonsteroidal anti-inflammatory drugs, steroids, or just an expectant attitude $[2,5]$. Surgical resection is not usually recommended [2]. In general, the prognosis is good [2, 3].

\section{Statement of Ethics}

This study did not require informed consent nor review/approval by the appropriate ethics committee.

\section{Disclosure Statement}

The authors declare no conflicts of interest.

\section{References}

1 Yang X, Zhu J, Biskup E, Cai F, Li A. Inflammatory pseudotumors of the liver: experience of 114 cases. Tumour Biol. 2015 Jul;36(7): $5143-8$.

2 Soares M, Honovar M, Pimentel Barbosa J. Pseudotumor inflamatório do fígado: o imitador bom das neoplasias hepáticas. Galicia Clin. 2014;75(1):36-8.
3 Park JY, Choi MS, Lim YS, Park JW, Kim SU, Min YW, et al. Clinical features, image findings, and prognosis of inflammatory pseudotumor of the liver: a multicenter experience of 45 cases. Gut Liver. 2014 Jan;8(1):58-63.

4 Patnana M, Sevrukov AB, Elsayes KM, Viswanathan $\mathrm{C}$, Lubner M, Menias CO. Inflammatory pseudotumor: the great mimicker. AJR Am J Roentgenol. 2012 Mar;198(3):W21727.
5 Conceição JS, Santos AM, Júnior LEF, Braga HJV, Silva LR. Pseudotumor inflamatório do fígado - um diagnóstico diferencial raro de massa hepática. GED Gastroenterol Endosc Dig. 2012;31:102-106. 